\title{
REFLEXIVE MECHANISMS OF MODERN EDUCATIONAL ACTIVITY
}

Kuznetsova A.Ia.

Novosibirsk State Pedagogical University, Novosibirsk,e-mail: phileducation@yandex.ru

The article discusses the problem of the transition of theoretical and practical educational activities to a reflective level of thinking. The content of the concepts "reflection" and "reflexivity", "reflexive mechanism of thinking" on the basis of their presentation in modern scientific research on philosophy, psychology, pedagogy is clarified. It is proposed to consider reflective mechanisms of thinking as tools for correlative a person with his environment. The methodological role of reflection in human consciousness is presented - the role of feedback, necessary to clarify the quality of cognitive activity. It is shown that the foundation of the concept of intellectual reflection was laid in the works of domestic scientists - philosophers and psychologists of the second half of the 20th century. It is concluded that the filling of society with intellectual systems based on digital technical means leads to the need to increase the methodological level included in the intellectual system of human natural intelligence. As a result, the scientific relevance of the triad is emphasized: the practice of education, study of the educational process and the reflectivity of the teacher.

Keywords: educational activity, reflective comprehension, reflective-intellectual level, reflexive-methodological approach, self-knowledge

The development of modern education is motivated by numerous changes in the social environment. At the same time, significant methodological changes were made in the theory of the humanities. This state of affairs makes it possible to reasonably accept or reject the proposed innovations, based on a general philosophical understanding of the processes of education. Currently, when discussing the problems of the development of education, it becomes relevant to master the system of new psychological and pedagogical knowledge in the field of intellectual reflection. Modern scientific achievements in the field of reflective thinking make it possible to comprehend both strategic problems and educational projects, and to strengthen the significance and meaningfulness of elementary steps in the practice of education by transferring a teacher from a purely technical activity to a meaningful research reflective. The development of the concept of "reflection" at the present stage of pedagogical science is expanding. Along with a deeper study of the nature of reflection, a spectrum of possibilities for using this phenomenon in the practice of education as "reflection mechanisms" is being studied.

\section{Literature review}

The ideas about the mechanisms of intellectual reflection are used to solve numerous problems and when discussing the problematic aspects of education (Opalyuk T.) [1]. In the methodology of heterogeneous studies of educational problems, a transition to a reflective level of thinking is observed (Pikalova E.A.) [2]. The following are studied: various technologies for the organization of reflexive analysis (Muhametdinova S.H.) [3]; the formation of reflective skills (Merkulova U.Y.) [4]; metacognitive level of reflection
(Kraeva A.G.) [5]; technology for the development of reflective teacher competence (Merzon E.E.) [6]; general problems of reflexive behavior (Curtis C.E., D’Esposito M.) [7]; reflective dialogue in the educational process; reflective method in the development of professional thinking; reflexive analysis of methodological activities; ethics of reflexive relationships (Etherington K.) [8]. and etc.

Reflection as a special type of mental reality has become the subject of research by modern psychologists, philosophers, and educators. Since reflection is one of the fundamental scientific categories and part of the concepts of many modern scientific fields that study man, the science continues to refine the content of the concepts of "reflection" and "reflexivity". Initially, the concept of "reflection" arose in philosophical science. According to Descartes, "reflection is the ability of the mind to follow its own actions." A more widely understood reflection is a form of theoretical human activity aimed at comprehending this activity, this is the activity of self-knowledge, revealing the specifics of the human spiritual world. The conversion of reflection on the soul allows a person to see, reflect his inner spiritual world. Reflection is a way to become a researcher, observer in relation to his actions, his thoughts. The reflexive mechanism of a person performs the function of control necessary to coordinate his mental activity with the environment. Appeal to reflective mechanisms in modern scientific research when comprehending numerous and diverse educational processes indicates a search for a methodological transition to a higher intellectual level. The formulation and solution of the general task of the development of education plays a unifying role. At the same time, the development of natural individual mechanisms of reflection of a person allows 
him to fulfill the function of personal control, necessary to coordinate his mental life with society and his educational environment. Mastering the mechanisms of reflection in educational activity allows us to combine the processes of self-knowledge, revealing the specifics of the spiritual world of a person with the study of all the various intellectual processes of the educational system [9].

\section{The problem and purpose of the study}

The problem is that, given the richness and sufficient depth of the available research, methodologically they are not united by the common goals of mastering the reflexive-intellectual level in the development of education. The consistent use of reflective thinking mechanisms in all elements and structures of the educational process and the integration of research projects in education based on the reflexivemethodological approach will allow the education system to rise to a higher level that corresponds to the modern scientific and technical information society. The purpose of the article is to show the importance of understanding the reflective mechanisms of educational activity and the methodological foundation of scientific pedagogy to the transition to a reflective level of study of educational processes.

Technologically, reflection is self-observation, methodologically - a category of consciousness. At the same time, it is different from awareness and comprehension. Reflection is a form of realization of personality in mental activity, necessary for the active rethinking of the content of individual consciousness. The search for a place of reflection in a person's spiritual life leads to questions about the correlation of concepts: consciousness, soul, personality, intellect. We can proceed from the ideas of Locke J. that consciousness is something more than a soul, or stop on the statement of Titchiner E.B. on the equivalence of the soul and consciousness. According to Seneca, intelligence is part of the soul, its best part. In the spiritual world of man, the mechanisms of reflection play a role and perform the corresponding functions.

The methodological movement to develop reflective thinking mechanisms at the turn of the 1960s -70 s. led to the conceptualization in the system-activity methodology of such innovations as "configuration", "tabloization of consciousness", "reflexivity of management", etc. (Semenov I.N.). In applied terms, awareness of the means and methods of thought activity was realized in the design activities of Alekseev N.G. [10], Sazonov B.V., Shche- drovitsky G.P., in the studies of psychologists Davydov V.V., Ilyasov I.I., Rubtsova V.V., Slobodchikov V.I. The foundation of psychological and pedagogical research of reflection is contained in Thales's aphorisms: "Know thyself", Socrates "I only know that I don't know anything", and the basis of reflective thinking mechanisms is manifested in Socrates's dialogues. As a result of many years of diverse studies in the field of general, age, social, pedagogical and engineering psychology, it was possible to experimentally differentiate reflection (Semenov I.N.) into its types such as intellectual, personal, dialogic, communicative, cooperative. In various discourses their own special types of reflection are formed: existential, cultural, spiritual. Given this differentiation of reflexive processes, the direction of reflexivity in solving creative problems was developed. "Since, in contrast to this, we were interested in the heuristic role of reflection in the process of problematic and productive thinking, then in the constructive opposition to the sociotechnical interpretation of reflection (Lefebvre V.A., Smolyan G.L.) and in the dialectic-activity approach (Davydov V.V., Ilyenkov E.V.) we proceeded to a theoretical and experimental study of reflexive processes based on the material of discursive solution of creative problems.

The basis for the development of a reflexive approach in social psychology was the work of V.A. Lefebvre. In the development of domestic natural-science and socio-technical concepts of reflection, Rozov V.A., Ladenko I.S., Lepsky V.E., logical and mathematical versions of the reflexive control of Lepsky V.E., Trudolyubov A.F. showed the influence of ideas and methods. His rationalist ideas influenced the psychological and pedagogical study of reflection. In the 1970s, Davydov V.V., and later his scientific school (Zak A.Z., Zakharova A.V. and Botsmanova M.E., Rubtsov V.V., started the psychological and pedagogical study of reflection). Katrich-Davydova I. and others.). In these works, reflection is treated purely rationalistically - as intellectual reflection.

The concept of intellectual reflection Ladenko I.S. was formed in connection with his development of the methodology of intelligent systems. Ladenko I.S. pointed to the methodological need for a reflective-intellectual approach in his studies of social systems. Such a problem was caused by the conditions of modern scientific and technological progress, the development of intellectual activity in the 20th century, the mass education, the functioning of complex organizational forms of scientific knowledge, engineering, managerial and 
educational activities. The combined groups of functionally organized specialists and the integrated complexes of cognitive tools used by them were called intelligent systems. The patterns of their formation, functioning and development are investigated by a complex field of knowledge, called the theory of intelligent systems. An immediate reason and initial ground for creating ideas about intelligent systems was the analysis of substitutions of the natural receptors of a person and his brain by technical receptors and computers. With such substitutions, a redistribution of cognitive operations occurs between the natural organs of people and technical devices that combine and function together when performing complex cognitive processes. In each case, an intelligent system is formed, which is a functionally organized team of specialists and the technical means of cognition they use. Ladenko I.S. showed that such systems are self-organizing and reflective.

\section{Research results and discussion}

Studies of thought activity, covering the problems of intellectual reflection, have shown that reflection can become a central factor combining the knowledge of nature external to the subject and its internal nature, thus balancing the person with nature from which he was isolated artificially by the cognition procedure. At the same time, in order to comprehend the personality as a social product, the human model must be supplemented with personal reflection. As a result, the idea of a reflective personal intellectual education of a modern person is formed.

Since reflection is a form of theoretical human activity, it can be aimed at maximizing generalizations in relation to the processes of education, while exercising the function of monitoring educational activity. The initial ideas of reflexive control were formulated to control the enemy in conflict situations. Forms and techniques of reflective control are defined by Lefebvre V. A. as an impact on the subject, inciting him to make a decision prepared in advance by the administering party. Developing the theory of reflexivity, Lefebvre V.A. illustrated the possibility of playing an action before an action, i.e. reflexivity of action and its fundamental subjectivity. In these studies, the study of self-organizing and self-reflective systems begins, which opened up the possibility of studying the processes associated with individual consciousness and self-consciousness. Lefebvre V.A. builds, using the concept of "reflection", a formal model of the inner world of a person that has nothing to do with his biological nature, analyzes the actions of people in a situation of moral choice between good and evil, using the obtained model of reflection [11]. The study of reflective management in education requires special reflection, a systematic approach and consideration of objective systemic laws that exist in nature, society, science and technology. In such studies, reflexivity must be considered along with other systemic principles, such as integrity, self-development, self-knowledge, etc. [12].

Reflective processes are most clearly manifested not only in conflict situations and rivalry, but also in cooperation and partnership. It is this situation - implicit compulsory orientation when the subject chooses the solution - that Lefebvre V. called reflexive control. The choice of a solution in a conflict situation is made in the same way as in the implementation of the pedagogical principle of free education at Rousseau: the main problem is precisely to get rid of freedom of choice, hard to bring to the desired solution, while maintaining confidence that the choice is free. In the theory of reflexive control, this is called forced orientation. If we follow in practice the ideas of Jean Jacques Rousseau, then for the realization of the "principle of free education" preliminary reflection of all factors influencing the educated person and the whole complex of educational conditions is necessary. In order for such manipulation not to be rejected in the process of exposure, and to bring a positive result, it is necessary to monitor the preservation of the subjectivity of the pupil.

The reflection of the practically important tasks of training and education is applicable both in the process of training and education, and in the process of students' independent work. It also makes the problem of the "subject" of research relevant and changes the content of the "object" of research. In natural science, the researcher is opposed to the object only in the study of matter not endowed with the psyche. In the study of the same object "endowed with the psyche" between the researcher and the subject of research, the subject-subject relations are formed. In the context of the subjective approach, the researcher focuses on the problems of the psychology of consciousness. In the future, the construction of models of human consciousness becomes one of the main directions of domestic cognitive science. With the functioning of reflection, the individual as a subject assumes responsibility for the course of his life, his actions acquire a philosophical connotation. At the same time, reflection, 
which is used as a means of self-education of the mind, can serve as an instrument of influence from the outside, become a prerequisite for creating the conditions for manipulating the consciousness of those brought up.

The "reflexive movement" in science, the deepening of the reflexive discourse in education, leads to the emergence of such new scientific areas as the epistemology of pedagogical practice, the formalization of professional pedagogical activity. To identify the teacher's competencies within the framework of the reflexive paradigm, it is proposed to clarify the difference between a theoretical researcher, a purely practitioner, and a practitioner who thinks about what and how he does it. Reflective understanding of the processes of training and education involves the integration of the principle of reflexivity and activity approach, which includes a mental reflection of the activity, and also suggests the possibility of adjustment in the process of activity. In practice, the solution to the problem of moving to a reflective level of understanding the problems of education begins with the formation of the reflective skills of the teacher. At the same time, a model of a reflecting teacher is being formed, in which he takes on the role of a researcher. A professional educator is daily found between research and teaching practice. In professional activities, the reflective task of a specialist is to observe their own actions, both real and virtual. A thinking practitioner has a problem: how to act, thinking about what he is doing. The daily research approach encourages the teacher to reflect on his professional identity. The problem of "reflection" has not yet been posed in domestic pedagogical science of the first half of the twentieth century, but the reflexive connection between theory and practice has been widely implemented in the works of Shatsky S.T., Blonsky P.P., Kapterev P.F., Makarenko A.S. et al. So, for pedagogical thinking Shatsky S.T. was characterized by an understanding of the essence of pedagogical phenomena, reflection on the causes of failures, difficulties, comparison, analysis, generalization of individual observations. The reflective practice of the teacher-thinker became the basis for domestic teachers in establishing the basic laws of the process of education and the further implementation of their theoretical reflection.

Teachers-researchers see an increase in the level of their professional activity in an ever deeper and more subtle penetration into the reflective areas of control and feedback in the educational process. So, the virtual triangle between the practice of education, studies of the educational process and the reflectivity of the teacher becomes the subject of reflection. The development of a model of a reflecting researcher-teacher requires formalization of knowledge about professional activity, reflection of the activity of a "researcher-practitioner" "step by step", individual techniques: "La prise de recul" - a step back, etc. Bernard Wentzel also suggests reflecting individual states and positions of a teacher in the reflection of practice: L'attitude empathique - "empathy" in the "listening position" - a form of responsibility for another; "Position d'écoute." - "listener position" from the practice of scientific interviews; "La capacité à observer" - "The ability to observe"; Know-how, allowing to analyze real metacompetencies necessary for building professional skills. Such detailing of the teacher's activities leads to the development of a teacher's professional competency model within the framework of the reflexive paradigm.

A detailed study of reflection has led to an increase in the subject area of methodological knowledge. Of particular typological importance was reflection in the writings of Ladenko I.S. Its functions in intelligent systems were correlated with the operation of reproductive and structural models. The phenomenological interest in reflection was expressed in the development of epistemological, logical, intellectual, sociological and other scientific approaches. In pedagogical theory, the categories of intellectual and personal reflection are used in the development of the most general and initial concepts of education of modern man.

The development of a reflexive paradigm for the development of education on the foundation of reflexive control currently has favorable conditions in the practice of education. A transition to the reflexivity of professional thinking will take place. Reflective control of thought in action and in the aftereffect allows you to make adjustments to pedagogical work, to teacher training, to the practice of psychological and pedagogical research, to the development and implementation of educational intelligent systems. This improves the quality of thinking in all educational activities [13]. The simultaneous development and deepening of the classical system-activity methodology in solving the problems of the development of education and the formation of a model of a reflecting teacher, its reflective competencies, allow us to combine disparate reflective issues into an integrated model. 


\section{Conclusions}

In a society that has embarked on the path of intellectualization in the 20th century, a movement towards further development in this direction is supported. Along with the interest in the intellectual development of the individual in social sciences, a direction of reflective understanding of both thinking and educational practice is being formed. The transition of the science of education to a reflective level becomes a definite leap in the development of the entire educational system. Such a change in development becomes possible since it occurs on the basis of the self-awareness of pedagogy of self as a science prepared during the 20th century. A sharp transition in the reflexive development of pedagogy at the beginning of the XXI century became possible, since by this time the formation of science-pedagogy was enriched by the development of its methodological foundations [14]. The intellectual development of society, together with the methodological capabilities of pedagogy, created the conditions for the further development of pedagogical science. As a result, we observe reflection on the reflexive level of education management, design and strategic development of education, a reflection of the teacher's practical activities, turning into a reflection of the methods of practice and thinking. All taken together allows us to set the goal of forming an updated paradigm of the philosophy of education. On this new basis, it becomes possible to implement meaningful educational practices while maintaining humanistic priorities: self-knowledge, self-development and self-education, individual trajectory in education. In addition, science, based on the methodological achievements of the second half of the 20th century in the field of genetic logic, gets the opportunity to go on to evaluate the effectiveness of new reflective techniques.

\section{References}

1. Opalyuk T. Defining concepts of "reflection", "reflexive position", "reflexive skills", "reflexive competence", "reflexive culture": comparative and analytical review web of scholar. 2017. № 5 (14). P. 64-68.

2. Pikalova E.A. Reflexive organization of learning and cognitive activity of students in technical institutions European journal of education and applied psychology. 2015. № 2 . P. 20-22.

3. Muhametdinova S.H., Filimonov Y.A., Fomenko A.A Reflexive film script as technology of the humanitarian support of reflexive analysis // Collection of scientific papers. 2013. V. 16. № 3. P. 24-26.

4. Merkulova U.Y. Conditions of formation of reflexive skills of adolescents // сборнике: Young scientist USA education. auburn, USA, 2014/ P. 126-130.

5. Kraeva A.G. Science art as a metacognitive level of reflection of modern culture // Simbirsky Scientific Herald. 2017. No. 4 (30)/ P. 81-88.

6. Merson E.E., Nurgatina I.E., Barkhayeva G.M. The technology of teacher reflexive competence development in modern conditions // Review of European Studies. 2015. V. 7. № 4. P. 112-117.

7. Curtis C.E., D'Esposito M. Success and failure suppressing reflexive behavior // Journal of cognitive neuroscience. 2003. V. 15. № 3. P. 409.

8. Ethrington K. Ethical research in reflexive relationships // Qualitative inquiry. 2007. V. 13. № 5. P. 559-616.

9. Kuznetsova A.Ya. Integrality of human nature and his knowledge // international journal of applied and fundamental research. 2013. № 2. P. 306,

10. Alekseev N.G., Karpov A.V., Semenov I.N., Solondaev V.K. Philosophical foundations of reflexive approach // Reflexive approach to psychological educational support. M., IRPTiGO, Yaroslavl, 2004. P. 11-17.

11. Lefebvre V.A. The supreme values and formal theory of the choice // Voprosy filosofii. 2012. № 4. P. 154-157.

12. Lepskiy V. Ethical Models of V.A. Lefebvre in the Context of Development of Scientific Rationality // Russian Journal of Philosophical Sciences. 2016;(8). P. 40-53.

13. Kuznetsova A.Ya. The humanistic value of intellect in education // European journal of natural history. 2009. № 3. P. $72-73$.

14. Kuznetsova A.Ya. The role of the picture of the world in the personal and competency training of a specialist // European journal of natural history. 2020. № 2. P. 10-14. 